\title{
Analysis of Principal Gas Products During Combustion of Polyether Polyurethane Foam at Different Irradiance Levels
}

\author{
Lucas Bustamante Valencia, ${ }^{\mathrm{a}, \mathrm{b}}$, Thomas Rogaume ${ }^{\mathrm{a} *}$, Eric Guillaume ${ }^{\mathrm{b}}$, \\ Guillermo Rein ${ }^{c}$, and Jose L. Torero ${ }^{c}$ \\ ${ }^{a}$ Laboratoire de Combustion et de Détonique, UPR 9028 CNRS, ENSMA, BP 40109, \\ 86961 Futuroscope, France. \\ ${ }^{\mathrm{b}}$ Laboratoire national de métrologie et d'essais, Fire Behavior and Fire Safety \\ Department, 78197 Trappes Cedex, France. \\ ${ }^{c}$ BRE Centre for Fire Safety Engineering, The University of Edinburgh, \\ $\mathrm{EH}_{9} 3 \mathrm{JL}, \mathrm{UK}$.
}

\begin{abstract}
This paper studies the release of the principal gas species produced during the combustion of a non-flame-retarded Polyether Polyurethane Foam (PPUF) of density of $20.9 \mathrm{~kg} \cdot \mathrm{m}^{-3}$ in the cone calorimeter. Five irradiance levels are studied: $10,20,30,40$, and $50 \mathrm{~kW} \cdot \mathrm{m}^{-2}$. Heat release rate, mass loss rate and bulk gas mass flow are measured. The mass flow and yields of gas species are measured as well. The analysis of release of gas species relative to time allowed to study the different stages of PPUF kinetics and to quantify the gas composition. Of the twenty two different gas species that were monitored simultaneously, the principal species found were $\mathrm{CO}_{2}, \mathrm{CO}, \mathrm{H}_{2} \mathrm{O}, \mathrm{NO}$ and total hydrocarbons. According to species release, two decomposition stages for PPUF are identified. In the first stage, the solid structure breaks down carrying the decomposition of isocyanate, and in the second stage the polyol decomposes. These two stages are in agreement with the decomposition mechanism proposed in literature. However, the data presented here is the first experimental study of burning behavior of PPUF taking into account the release of gas species too. An elemental analysis was performed and the chemical formula of the virgin material was determined. This allows the mass balance of the elements in the virgin foam content with the gaseous product content. The effective heat of combustion and the ratio between heat release rate and $\mathrm{CO}_{2}$ mass flow are calculated at each of the irradiance levels.
\end{abstract}

*Corresponding author; e-mail: thomas.rogaume@lcd.ensma.fr; Phone: +33 5492498 31; Fax: +33549082336. 


\section{Keywords}

PPUF, flame retardant, Cone calorimeter, FTIR, FID, pyrolysis, thermal decomposition

\section{Notation}

\begin{tabular}{|c|c|c|}
\hline$A$ & $\begin{array}{l}\text { Area of the solid sample (0.0088 in this } \\
\text { work) }\end{array}$ & {$\left[\mathrm{m}^{2}\right]$} \\
\hline$a_{i}$ & Slope of the straight line at irradiance level i & {$[-]$} \\
\hline$b_{i}$ & $\begin{array}{l}\text { Y-intercept of the straight line at irradiance } \\
\text { level i }\end{array}$ & {$[-]$} \\
\hline$C$ & Orifice plate calibration constant & {$\left[\mathrm{kg}^{1 / 2} \cdot \mathrm{m}^{1 / 2} \cdot \mathrm{K}^{1 / 2}\right]$} \\
\hline$E$ & $\begin{array}{l}\text { Heat of combustion per unit mass of oxygen } \\
\text { consumed (13.1 in this work) }\end{array}$ & {$\left[\mathrm{MJ} \cdot \mathrm{kgO}_{2}^{-1}\right]$} \\
\hline EHC & Effective heat of combustion & {$\left[\mathrm{kJ} \cdot \mathrm{kg}^{-1}\right]$} \\
\hline HRR & Heat release rate per unit area & {$\left[\mathrm{kW} \cdot \mathrm{m}^{-2}\right]$} \\
\hline MLR & Mass-loss rate & {$\left[\mathrm{g} \cdot \mathrm{s}^{-1}\right]$} \\
\hline$\dot{m}_{b}^{\prime \prime}$ & Mass flux of species b & {$\left[\mathrm{g} \cdot \mathrm{s}^{-1} \cdot \mathrm{m}^{-2}\right]$} \\
\hline$\dot{m}_{b}$ & Mass flow rate of species b & {$\left[\mathrm{g} \cdot \mathrm{s}^{-1}\right]$} \\
\hline$\dot{m}_{e}$ & Mass flow rate at exhaust duct & {$\left[\mathrm{kg} \cdot \mathrm{s}^{-1}\right]$} \\
\hline$M W_{b}$ & Molar mass of species $b$ & {$\left[\mathrm{~g} \cdot \mathrm{mol}_{\mathrm{b}}^{-1}\right]$} \\
\hline$P$ & Pressure & [atm] \\
\hline$R$ & Universal gas constant & {$\left[1 \cdot \mathrm{atm} \cdot \mathrm{mol}^{-1} \cdot \mathrm{K}\right.$} \\
\hline$R_{i}^{2}$ & Least-square fitness factor & {$[-]$} \\
\hline SMLR & Specific mass-loss rate (per unit area) & {$\left[\mathrm{g} \cdot \mathrm{s}^{-1} \cdot \mathrm{m}^{-2}\right]$} \\
\hline$T$ & Temperature of the gas mixture & {$[\mathrm{K}]$} \\
\hline$T_{e}$ & Gas temperature at flow meter & {$[\mathrm{K}]$} \\
\hline$X_{A}^{0}$ & Initial concentration of species A & {$[\mathrm{ppm}]$} \\
\hline$X_{A}$ & Concentration of species $A$ at time $t$ & {$[\mathrm{ppm}]$} \\
\hline$Y_{b}$ & Yield of gas species b & {$\left[g \cdot g^{-1}\right]$} \\
\hline$\dot{V}$ & $\begin{array}{l}\text { Volumetric flow in CC exhaust duct } \\
\left(2.4 \times 10^{-2} \text { in this work }\right)\end{array}$ & {$\left[\mathrm{m}^{3} \cdot \mathrm{s}^{-1}\right]$} \\
\hline $\operatorname{Vmol}_{b}$ & Volume of one mol of species b & {$\left[1 \cdot \mathrm{mol}^{-1}\right]$} \\
\hline$\Delta_{n}$ & Pressure difference across the orifice plate & {$[\mathrm{Pa}]$} \\
\hline & Oxygen depletion factor & {$[-]$} \\
\hline
\end{tabular}

\section{Abbreviations}

CC Cone Calorimeter

FID Flame Ionization Detector

FTIR Fourier Transform Infrared spectroscopy analyzer

ND-IR Non Dispersive Infrared analyzer

LNE Laboratoire national de métrologie et d'essais

PMMA Polymethylmethacrylate

PPUF Polyether Polyurethane Foam 


\section{Introduction}

The total production of polyurethane in Western Europe in 2007 was about 3.7 million tons and should be around 4.1 millions tons in 2012. In 2007, the distribution of various polyurethanes used was: $29 \%$ rigid foams, $37 \%$ flexible foams, $12 \%$ elastomers and $12 \%$ coatings [1]. Polymeric foams are ubiquitous in the modern built environment and, in general, a significant fire safety concern due to their common propensity towards medium to high flammability and toxicity. The limited knowledge and lack of extensive quantitative information on foam decomposition hinders further understanding of its burning behavior and related toxicity. More experimental and theoretical studies are required in order to develop better predictive tools. Polyether Polyurethane Foam (PPUF), the objective of this paper, is among the polymeric foams that need to be studied further.

The main application of flexible non-flame-retarded PPUF, such as used in this research, is in upholstered furniture for dwelling houses, offices and seats for vehicles [2]. This type of foam is commonly used in France, Italy, Spain, Portugal and several countries in Latin America among others [3] in which legislation does not require yet flame-retarded furniture materials.

This work is an experimental study of the reaction-to-fire of non-flame-retarded PPUF providing important understanding of its thermo-oxidative decomposition and evolved gases. PPUF data required in this research includes phenomena taking place in the gaseous and solid phases. The gaseous phase was characterized by measuring the mass flow of evolved gases as a function of time and Cone Calorimeter (CC) irradiance level. Mass-Loss Rate (MLR) was used to study the solid phase. Analyzing information from both phases provided very useful information about the chemistry of reactions taking place in the solid foam slab. In this paper, we used several experimental devices to study foam decomposition such as cone calorimeter, Fourier Transform Infrared spectroscopy analyzer (FTIR), Flame Ionization Detection (FID) and Infrared Non-Dispersive analyzer (ND-IR).

\section{Experimental setup}

An elementary analysis of the virgin PPUF used in this research was conducted by a combination of catharometry and ND-IR detection. Table 1 presents the composition along with the analysis methods. 
Table 1. Elementary analysis of the virgin PPUF.

\begin{tabular}{ccc}
\hline Element & Content & Method of measurement \\
\hline $\mathrm{C}$ & $61.90 \%$ & Catharometry by transformation on $\mathrm{CO}_{2}$ \\
$\mathrm{H}$ & $8.50 \%$ & Catharometry by transformation on $\mathrm{H}_{2} \mathrm{O}$ \\
$\mathrm{O}$ & $22.50 \%$ & ND_ IR by transformation on $\mathrm{CO}$ \\
$\mathrm{N}$ & $5.90 \%$ & Catharometry by reduction on $\mathrm{N}_{2}$ \\
$\mathrm{~S}$ & $<0.2 \%$ & ND_ IR detection \\
$\mathrm{Cl}$ & $<10 \mathrm{ppm}$ & N/A \\
\hline
\end{tabular}

The test reported in Table 1 was repeated three times and provided a precision of $\pm 0.3 \mathrm{wt} \%$. Results accounted for up to $98.8 \%$ of the total mass of the sample, with the remainder attributed to inert ash. The elementary analysis showed that no inert load, flame retardants or fillers were used during the manufacturing of PPUF; neither chlorine nor sulphur-based additives were found. Based on the composition, the chemical formula of the virgin foam was determined to be $\mathrm{CH}_{1.53} \mathrm{O}_{0.27} \mathrm{~N}_{0.08}$. This chemical composition is in agreement with other Polyether Polyurethane Foams found in the LNE Materials Database ${ }^{1}$.

The reaction-to-fire characterization was carried out in a CC. PPUF specimens were conditioned at $23 \pm 2{ }^{\circ} \mathrm{C}$ and at a relative humidity of $50 \pm 5 \%$ for more than $88 \mathrm{hr}$ in accordance with the specifications of the ISO 291:2005 standard [4]. The sample dimensions were $100 \pm 2 \mathrm{~mm}$ long, $100 \pm 2 \mathrm{~mm}$ wide and $50 \pm 2 \mathrm{~mm}$ high with a mass of $11 \pm 1 \mathrm{~g}$.

The evolved gases from the CC were passed through a desiccator and a cold trap to remove water vapor, thus improving the accuracy of the analyses. The paramagnetic analyzer used to measure the instantaneous oxygen concentration was a Servomex 4000 that includes an ND-IR for $\mathrm{CO}$ and $\mathrm{CO}_{2}$. Two additional gas analyzers were coupled to the exhaust duct of the CC, a Flame Ionization Detector (FID) and a Fourier Transform Infrared spectroscopy analyzer (FTIR). A FID Series AIX 2000 probe was connected at a gas sampling port upstream of the CC fan. The FID flow rate was $1.710^{-5} \mathrm{~m}^{3} \cdot \mathrm{s}^{-1}$, low enough to avoid affecting the main CC exhaust flow rate of $2.410^{-2} \mathrm{~m}^{3} \cdot \mathrm{s}^{-1}$. For simplicity, a FTIR Nicolet Magna IR 550 Series II (flow rate of $1.0 \times 10^{-4} \mathrm{~m}^{3} \cdot \mathrm{s}^{-1}$ ) was plugged to the exit of the CC exhaust. Sampled gas was transported to the measurement cell by a line heated to $180^{\circ} \mathrm{C}$. The FTIR gas measurement cell had a $10 \mathrm{~m}$ optical length and volume of 21 . The analyzer was calibrated to quantify more than twenty gas species simultaneously. A Eurotherm Chessell $4100 \mathrm{G}$ temperature register was used to measure the gas temperature in order to correct the molar flow rate of gas captured by FTIR.

${ }^{1}$ The LNE Materials Database is a proprietary tool created in 2006 and containing composition information of more than 5000 registers of industrial materials. 
Five irradiance levels were used: $10,20,30,40$ and $50 \mathrm{~kW} \cdot \mathrm{m}^{-2}$. Tests at 10,20 and $30 \mathrm{~kW} \cdot \mathrm{m}^{-2}$ were repeated four times, while those at 40 and $50 \mathrm{~kW} \cdot \mathrm{m}^{-2}$ were repeated twice. All the experiments were carried out under air atmosphere.

The density of the foam is $20.9 \mathrm{~kg} \cdot \mathrm{m}^{-3}$. Measurements were performed without an insulator on the bottom side of the sample. In order to analyze the influence of the insulator layer, tests were repeated using a $13 \mathrm{~mm}$-thick silica wool insulation layer with a density of $64 \mathrm{~kg} \mathrm{~m}^{-3}$ as described in the ISO 5 66o-1 standard [5].

\section{Results and analysis}

The heat release rate (HRR), an important variable for evaluating material fire hazards [6][7], was measured using the oxygen consumption calorimetry technique [8]. This technique is the basis of the ISO 5 660-1 standard [5] and uses Eq. (1) to calculate the HRR in $\left[\mathrm{kW} \cdot \mathrm{m}^{-2}\right]$. It is a function of $E$, the heat of combustion per unit mass of oxygen consumed (also known as the Thornton factor and assumed to be 13.1 $\left.\mathrm{MJ} \cdot \mathrm{kgO}_{2}^{-1}\right), \Phi$, the oxygen consumption factor defined in Eq. (2), and $\dot{m}_{e}$, the mass flow rate in the $\mathrm{CC}$ exhaust duct defined in Eq. (3) and determined from the pressure

$$
\begin{gathered}
H R R=1.10 \cdot E \cdot X_{O_{2}}^{o} \cdot\left[\frac{\Phi}{(1-\Phi)+1.105 \cdot \Phi}\right] \cdot \dot{m}_{e} \\
\Phi=\frac{X_{O_{2}}^{0}\left(1-X_{\mathrm{CO}_{2}}\right)-X_{\mathrm{O}_{2}}\left(1-X_{\mathrm{CO}_{2}}^{0}\right)}{X_{\mathrm{O}_{2}}^{0}\left(1-X_{\mathrm{CO}_{2}}-X_{\mathrm{O}_{2}}\right)} \\
\dot{m}_{e}=C \sqrt{\frac{\Delta p}{T_{e}}}
\end{gathered}
$$

drop across and temperature at an orifice plate.

In order to use these equations, some simplifications and experimental facts are required. The environmental $\mathrm{H}_{2} \mathrm{O}$ concentration was neglected because the exhaust gas passes through a calcium chloride filter and a cold trap in order to eliminate all moisture. $\mathrm{CO}$ concentration was also neglected because of its typically low concentration during flaming combustion. Calculations were carried out to verify the influence of neglecting the release of $\mathrm{CO}$, and the error was found to be less than $1 \%$. The calibration of the $\mathrm{CO}_{2}$ and $\mathrm{O}_{2}$ analyzers was conducted with pure nitrogen.

At the beginning of each test, the CC calorimeter thermal shield was opened and the sample was suddenly exposed to the set irradiance level. A decomposition front was formed and advanced rapidly from the top to the bottom of the sample. The results shown here correspond to flaming conditions initiated with a spark ignition source. In experiments not discussed in this paper, it was found that the critical irradiance level for ignition of the foam is $9 \mathrm{~kW} \cdot \mathrm{m}^{-2}$ and the irradiance level for auto-ignition is $35 \mathrm{~kW} \cdot \mathrm{m}^{-2}$.

Figure 1 shows the transient evolution of the mass loss rate (MLR) and HRR at the five different irradiance levels. 

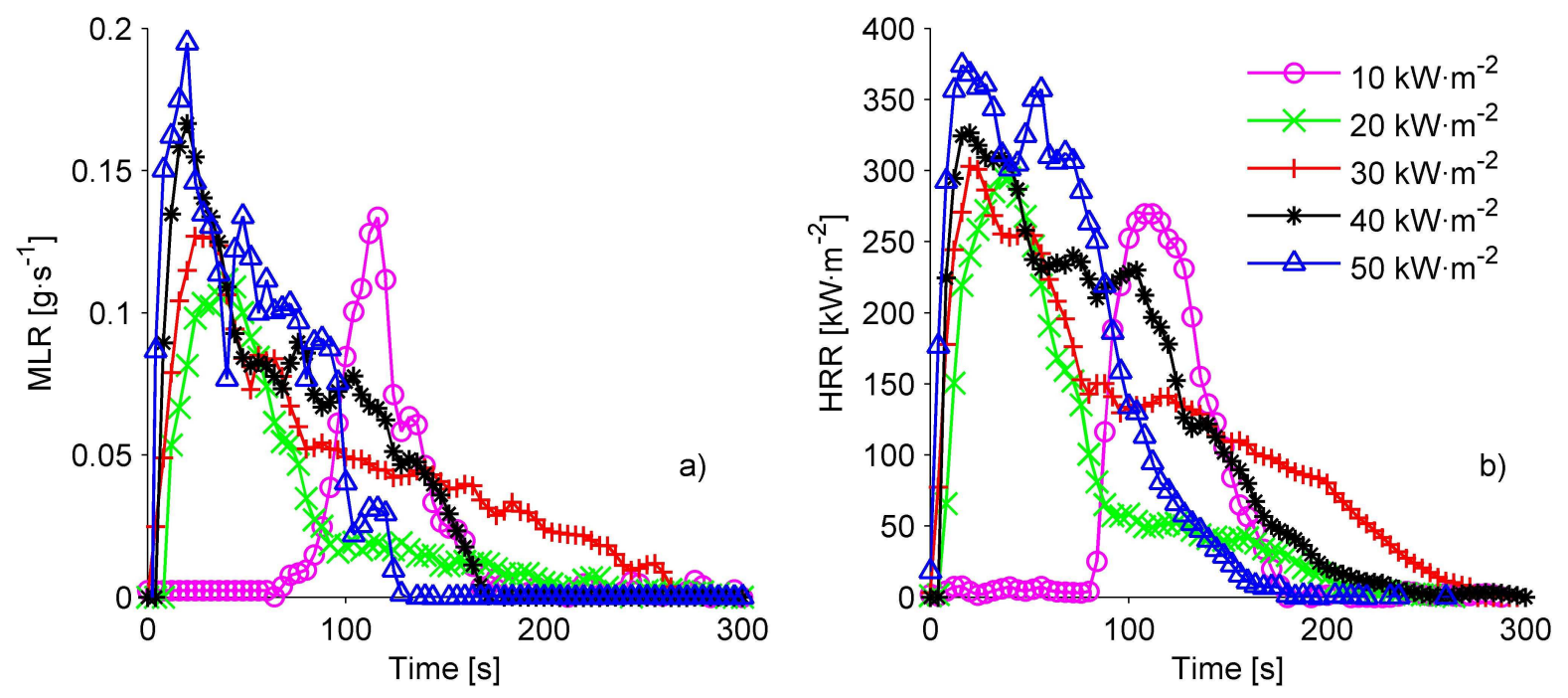

Figure 1. Results in cone calorimeter at five irradiance levels a) Mass-Loss Rate, b) Heat Release Rate

In Figure 1, time $t=0$ marks the beginning of the exposure to the desired irradiance level rather than the moment of ignition. As shown, the shapes of HRR and MLR curves changed with the irradiance level. At $10 \mathrm{~kW} \cdot \mathrm{m}^{-2}$, only one decomposition stage can be identified, while at 20,30 and $40 \mathrm{~kW} \cdot \mathrm{m}^{-2}$, two stages can be observed. The intensity of the secondary peak increases with the irradiance level and at an irradiance level of $50 \mathrm{~kW} \cdot \mathrm{m}^{-2}$, the second peak has a similar intensity to the first peak.

Table 2 presents the time to ignition, the time to extinction, the total combustion time of PPUF and the ratio between the burnt and initial masses.

Table 2. Experimental results of PPUF in CC measured at five irradiance levels: time to ignition, time to extinction, total combustion time and ratio between burnt and initial sample mass.

\begin{tabular}{ccccc}
\hline $\begin{array}{c}\text { Irradiance level } \\
\text { of CC } \\
{\left[\mathrm{kW} \cdot \mathrm{m}^{-2}\right]}\end{array}$ & $\begin{array}{c}\text { Time to } \\
\text { ignition } \\
{[\mathrm{s}]}\end{array}$ & $\begin{array}{c}\text { Time to } \\
\text { extinction } \\
{[\mathrm{s}]}\end{array}$ & $\begin{array}{c}\text { Combustion } \\
\text { time } \\
{[\mathrm{s}]}\end{array}$ & $\begin{array}{c}\text { Ratio of burnt } \\
\text { to initial mass } \\
{[\%]}\end{array}$ \\
\hline 10 & 87 & 176 & 89 & 41 \\
20 & 10 & 200 & 190 & 68 \\
30 & 5 & 273 & 268 & 97 \\
40 & 3 & 240 & 237 & 100 \\
50 & 2 & 173 & 171 & 98 \\
\hline
\end{tabular}

As expected in Table 2, time to ignition decreased when the irradiance level increased. Total combustion time is the difference between time to extinction and time to ignition. Total combustion times were shorter at low and high irradiance levels, with a maximum at $30 \mathrm{~kW} \cdot \mathrm{m}^{-2}$. This can be explained because for the low irradiance levels of 10 and $20 \mathrm{~kW} \cdot \mathrm{m}^{-2}$, the initial mass of the sample was not totally consumed during 
combustion. A significant amount of char remained in the sample holder after fire extinction. Thus, low irradiance levels provided shorter combustion times compared to the test at $30 \mathrm{~kW} \cdot \mathrm{m}^{-2}$, in which the sample is completely burned. At $50 \mathrm{~kW} \cdot \mathrm{m}^{-2}$, the decomposition reaction rate was faster than at $30 \mathrm{~kW} \cdot \mathrm{m}^{-2}$ due to the strong irradiance received by the sample from the radiant cone. It provided a shorter combustion time.

Comparison tests were performed using a silica wool insulating layer at the bottom face of the PPUF sample to investigate the effect of this boundary condition. The results show that decomposition kinetics, gas release and HRR do not change significantly with the insulating layer. This suggests that under the current test conditions, the decomposition rate is not controlled by sample heat losses.

In addition to the heat release rate, the toxicity of the burning products must be taken into account when analyzing the fire hazard of a material [9]. PPUF is manufactured from the condensation of polyisocyanates and polyether polyols in the presence of catalysts and/or additives [10][11]. Saunders et al. [12], Woolley [13] and Rogers et al. [14] studied the thermal decomposition of urethane-based plastics. They stated that, when PPUF is heated, urethane bonds break into polyol and isocyanate. In the first stage, isocyanate pyrolyses and oxidizes. It is released as yellow smoke. Liquid polyol remains in the sample holder as a semi-product of the decomposition process. Pyrolysis and oxidization of liquid polyol occur in a second decomposition stage. The gases released during a PPUF fire (burned and unburned), are considered highly hazardous to live safety and the environment [15][16][17].

Figure 2 presents the transient evolution of different gas species concentration, HRR and MLR at an irradiance level of $50 \mathrm{~kW} \cdot \mathrm{m}^{-2}$.

In Figure 2 the $\mathrm{x}$-axis is common for all curves. The concentrations of $\mathrm{CO}_{2}$ and $\mathrm{H}_{2} \mathrm{O}$ were quantified at the left hand side y-axis. The concentrations of $\mathrm{CO}, \mathrm{NO}$ and total hydrocarbons (THC) as well as the plots of HRR and MLR were quantified at the right hand side y-axis. Plot of MLR has been scaled by a factor of 200 for ease of viewing. Gas concentrations are expressed in [ppm], with THC units as the ppm equivalent of methane because of the FID calibration method. The results have been corrected for the transport delay and the response time of the instruments.

Figure 2 shows that the general change with time of the HRR, MLR and the curves of gases release are similar, thus suggesting the underlying kinetics throughout the burning process. This provided important information about solid decomposition reactions and production of gas species. The release curves for the different gas species did not have the same shapes, but did share common maxima and minima at various points in time. These common points represent the basis for the analysis of the PPUF decomposition kinetics and allowed identifying the PPUF decomposition stages.

As shown in Figure 2, at an irradiance level of $50 \mathrm{~kW} \cdot \mathrm{m}^{-2}$, the maximum in the HRR curve occurred approximately $17 \mathrm{~s}$ after the beginning of the exposure. Using the HRR peak as a reference, we can see that the first peaks of MLR, $\mathrm{CO}_{2}, \mathrm{CO}$ and NO occurred at exactly the same time. $\mathrm{H}_{2} \mathrm{O}$ was not considered as a hazardous gas, but it served as a marker for the occurrence of one particular reaction. This reaction involved the combustion of polyol and occurred during the second stage of decomposition (hydroxyl groups [18]). The curve corresponding to $\mathrm{H}_{2} \mathrm{O}$ concentration showed an 
important inflection point when the HRR reached to a maximum. However, with increasing time, the amount of $\mathrm{H}_{2} \mathrm{O}$ released continued to grow.

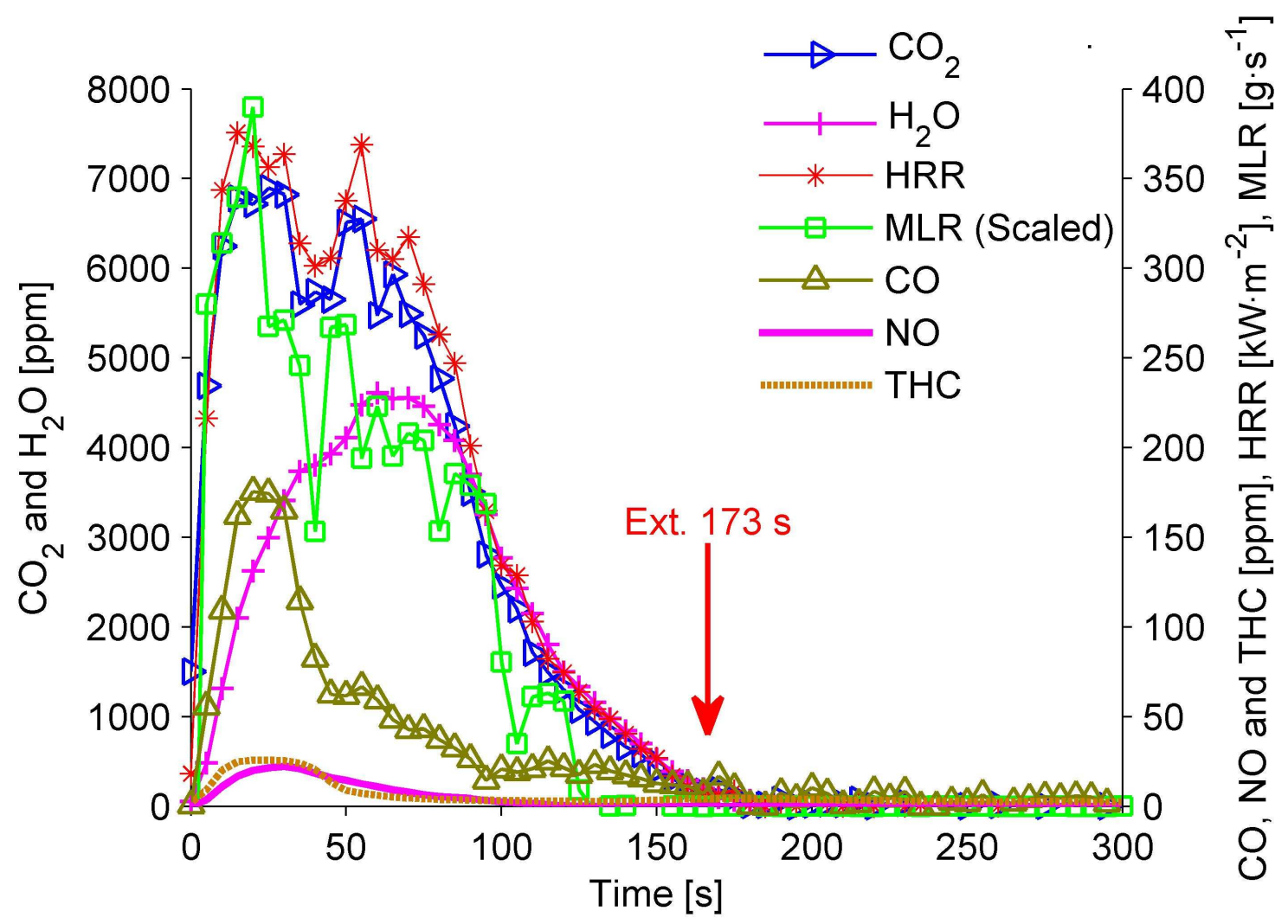

Figure 2. Change over time of HRR, MLR and gas species concentration during combustion of PPUF at an irradiance level of $50 \mathrm{~kW} \cdot \mathrm{m}^{-2}$ in $\mathrm{CC} . \mathrm{CO}_{2}$ and $\mathrm{H}_{2} \mathrm{O}$ are quantified at the left hand side $\mathrm{y}$-axis. $\mathrm{CO}, \mathrm{NO}$, THC, HRR and MLR are quantified at the right hand side y-axis. The MLR curve is scaled by a factor of 200.

The maximum release of $\mathrm{H}_{2} \mathrm{O}$ appeared $55 \mathrm{~s}$ after exposure to the $\mathrm{CC}$ irradiance. At about the same time, the second peak in the $\mathrm{HRR}$ and $\mathrm{CO}_{2}$ appeared, along with a local minimum of MLR, a local maximum of $\mathrm{CO}$ and an important decrease in the amount of THC production. At $50 \mathrm{~kW} \cdot \mathrm{m}^{-2}$, a third peak in the HRR curve appeared approximately $70 \mathrm{~s}$ after exposure to $\mathrm{CC}$ irradiance. This time corresponded to a maximum of $\mathrm{CO}_{2}$ release, a local maximum of MLR, the beginning of the decrease of $\mathrm{H}_{2} \mathrm{O}$ production and an important change in the slope of THC.

At $50 \mathrm{~kW} \cdot \mathrm{m}^{-2}$, before the second peak of HRR at approximately $50 \mathrm{~s}$, the solid has been completely consumed, leaving a semi-liquid residue in the holder. This dark brown viscous product consisted primarily of polyol with traces of isocyanate and oxidized residues. This semi-liquid product continued to oxidize as a pool fire until the extinction of flames, approximately $173 \mathrm{~s}$ after exposure to $\mathrm{CC}$ irradiance.

The evolution of gas species can be used to infer on the decomposition stages in the solid phase. In the $50 \mathrm{~kW} \cdot \mathrm{m}^{-2}$ test (Figure 2), from the beginning of exposure at $\mathrm{t}=0$ 
to approximately $50 \mathrm{~s}$ (about $48 \mathrm{~s}$ after flaming ignition), high concentrations of $\mathrm{CO}$, $\mathrm{CO}_{2}$ and $\mathrm{THC}$ were measured coming from the sample suggesting the presence of a rich combustible mixture. After 65 s, production of $\mathrm{CO}$ and THC were low, but the release of $\mathrm{CO}_{2}$ remained high (less rich combustible mixture). Hydrogen was consumed by the production of $\mathrm{H}_{2} \mathrm{O}$, and unburned molecules (total hydrocarbons) were negligible. The late release of $\mathrm{H}_{2} \mathrm{O}$ in comparison to $\mathrm{CO}_{2}$ suggested that the reaction of most hydrogenated compounds of foam were delayed.

Nitrogen is a minor chemical element in the foam, but present in the isocyanate chain. The FTIR analyzer was calibrated to measure nitrogenated compounds such as hydrogen cyanide $(\mathrm{HCN})$, ammonia $\left(\mathrm{NH}_{3}\right)$, nitrous oxide $\left(\mathrm{N}_{2} \mathrm{O}\right)$ and nitric dioxide $\left(\mathrm{NO}_{2}\right)$. In these experiments, except $\mathrm{NO}$, all other nitrogen gas species were absent or present in quantities under their detection limits ( $\mathrm{HCN}, 1.4 \mathrm{ppm} ; \mathrm{NH}_{3}, 1.7 \mathrm{ppm} ; \mathrm{N}_{2} \mathrm{O}$, $\left.0.5 \mathrm{ppm} ; \mathrm{NO}_{2}, 1.9 \mathrm{ppm}\right)$. As shown in Figure 2, $\mathrm{NO}$ release increased during the first $25 \mathrm{~s}$ of combustion. At $25 \mathrm{~s}$, the decomposition rate of foam was at its maximum and the mixture of gas products was fuel rich. This was a characteristic of the combustion of isocyanate and its higher volatility compared to polyol. After $25 \mathrm{~s}$, the NO production steadily decreased and at $75 \mathrm{~s}$, it was almost negligible. This suggested that all of the nitrogen contained in the isocyanate was released during the first stage.

Near $28 \mathrm{~s}$, the release of $\mathrm{CO}$ was at its maximum. At the same time, $\mathrm{H}_{2} \mathrm{O}$ release was increasing. With increasing time, the former decreased and the latter increased. This suggests that polyol began to react before the end of the isocyanate release. Thus, the combustion of polyol and isocyanate are not completely separated in time. The chemical analyses showed that the PPUF mass fractions of isocyanate and polyol were approximately $40 \%$ and $60 \%$, respectively. Therefore, in the first $28 \mathrm{~s}$, the majority of the mass loss would correspond to the decomposition of the isocyanate $(40 \%)$, with most of the remaining mass corresponding to the polyol (6०\%) that decomposes later.

Figure 3 presents HRR, MLR and the concentration of the main gases released on $\mathrm{CC}$ at an irradiance level of $10 \mathrm{~kW} \cdot \mathrm{m}^{-2}$. As in Figure 1, the initial time corresponds to initial exposure at the desired irradiance level.

The difference in curve shapes between 10 and $50 \mathrm{~kW} \cdot \mathrm{m}^{-2}$ (Figure 2 and Figure 3 respectively) allowed us to extract a divergence in gas release: the maximum concentration of $\mathrm{H}_{2} \mathrm{O}$ release for an irradiance of $10 \mathrm{~kW} \cdot \mathrm{m}^{-2}$ occurred at $140 \mathrm{~s}$. This corresponded to an inflection point of HRR (in addition to the single peak in the HRR curve), the second peak of MLR, a local minimum of $\mathrm{CO}$ and the beginning of the decrease in NO release. Any further decomposition stages could be clearly identified at this irradiance level. The thermal mechanism for PPUF decomposition analyzed in this work was validated for the five irradiance levels studied.

At all studied CC irradiance levels, the curves for HRR and $\mathrm{CO}_{2}$ release have similar shapes. However, the correlation between these two values may be more complicated than the shapes suggests, since HRR was measured as a function of the oxygen depletion in air. This proportion is highly influenced by characteristics of the material being burned, such as high oxygen content in the molecular structure [19]. 


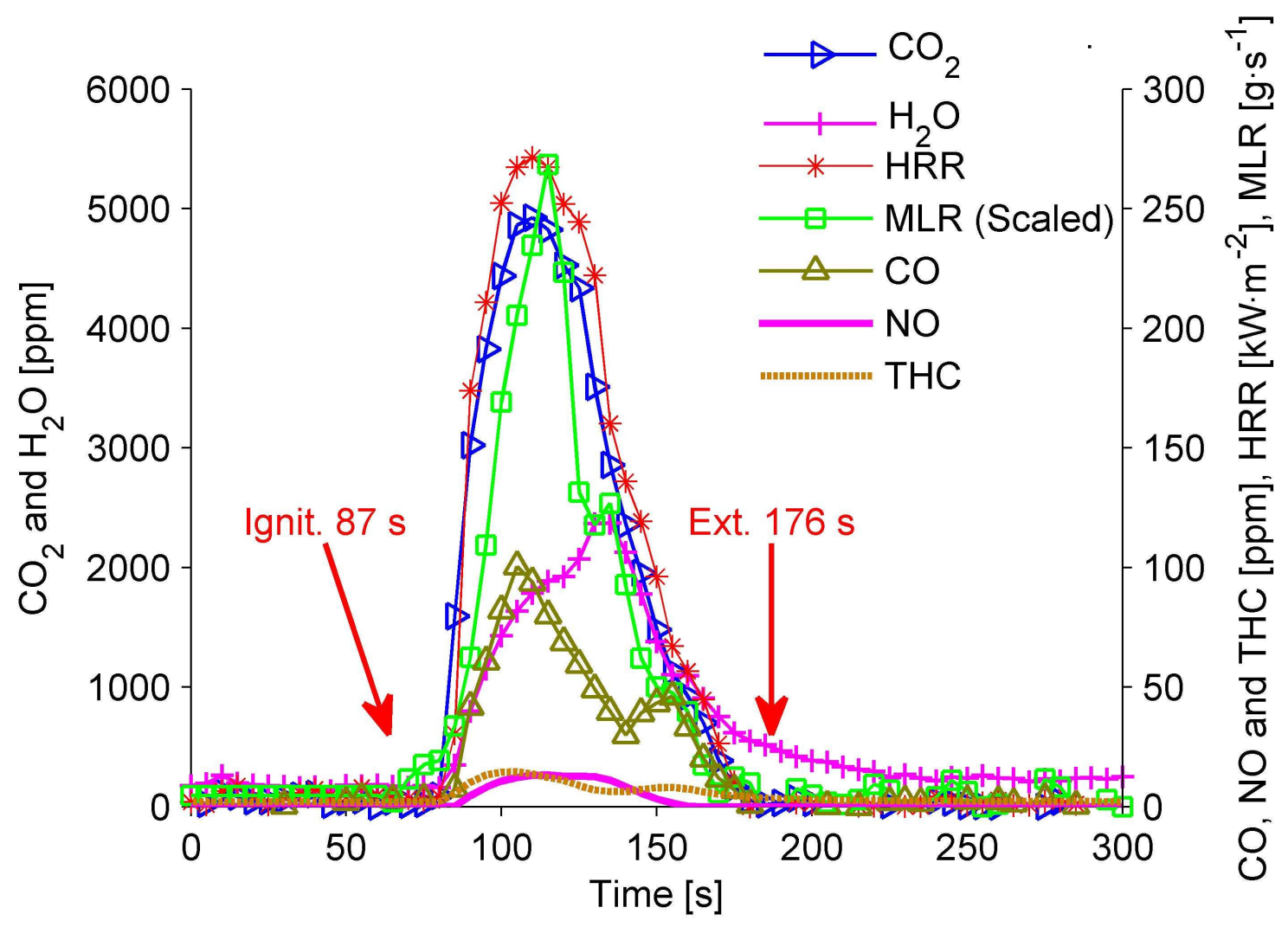

Figure 3. Change over time of HRR, MLR and gas species concentration during combustion of PPUF at an irradiance level of $10 \mathrm{~kW} \cdot \mathrm{m}^{-2}$ in $\mathrm{CC} . \mathrm{CO}_{2}$ and $\mathrm{H}_{2} \mathrm{O}$ are quantified at the left hand side $\mathrm{y}$-axis. $\mathrm{CO}, \mathrm{NO}$, THC, HRR and MLR are quantified at the right hand side y-axis. The MLR curve is scaled by a factor of 200.

The following equations allow the calculation of yield of gaseous species:

$$
\begin{gathered}
Y_{b}=\frac{\dot{m}_{b}}{M L R} \\
\dot{m}_{b}=X_{b} \cdot \dot{V} \cdot \frac{M W_{b}}{V m o l_{b}} \\
\operatorname{Vmol}_{b}=\frac{R \cdot T}{P}
\end{gathered}
$$

The yield of a gas species, expressed in Eq. (4), is the ratio between the mass flow rate of the species out of the sample and the mass-loss rate of foam. The mass flow rate of a species, expressed in Eq. (5), is given by: the product of the species concentration, 
the volume flow rate in the exhaust line times, the molar mass divided by the volume of one mole of the species. Eq. (6) is used to calculate the volume of one mole of species $b$.

The mass flux of a gas species is calculated as the mass flow rate divided by the area of the solid sample $\left(\dot{m}_{b}^{\prime \prime}=\dot{m}_{b} / A\right)$. Figure 4 shows the mass flux for four principal gas species $\mathrm{CO}_{2}, \mathrm{CO}, \mathrm{NO}$ and THC, at three irradiance levels 10,30 and $50 \mathrm{~kW} \cdot \mathrm{m}^{-2}$.
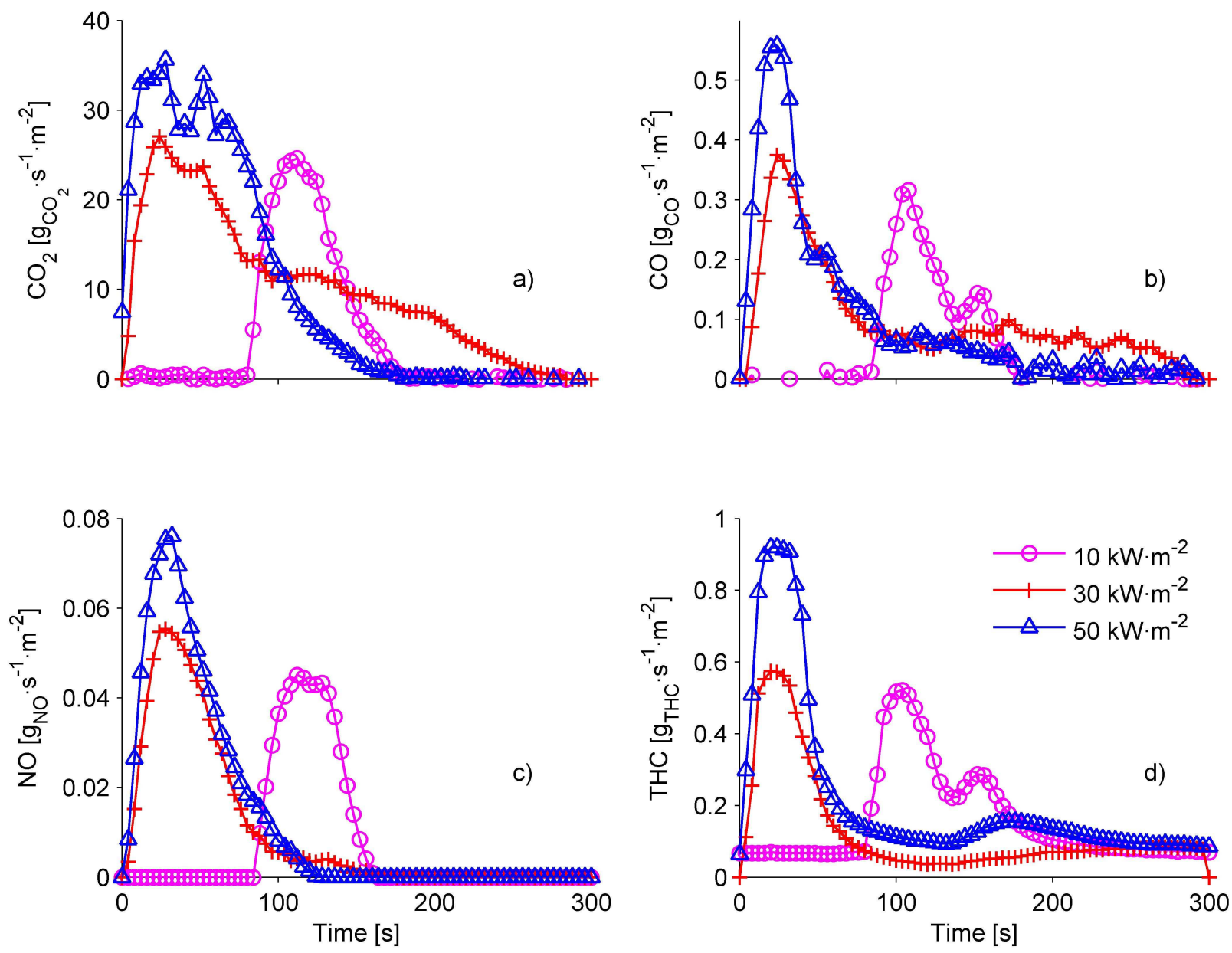

Figure 4. Evolution of mass flow at three irradiance levels 10, 30 and $50 \mathrm{~kW} \cdot \mathrm{m}^{-2}$ for four gas species: a) $\mathrm{CO}_{2}$, b) $\left.\left.\mathrm{CO}, \mathrm{c}\right) \mathrm{NO}, \mathrm{d}\right) \mathrm{THC}$.

The curves of Figure 4 confirmed that the toxic hazard of PPUF combustion changed with the time. The maximum toxicity occurred in the first $150 \mathrm{~s}$ of the fire. The mass flux of total hydrocarbons (Figure 4-d) allowed us to conclude that at all irradiance levels, THC release rose steeply between two and four seconds prior to ignition. This would explain the presence of a volatile combustible mixture at the surface of the sample prior to ignition. The results in Figure 4 also allowed for the calculation of total gas compounds released, given in Table 3 . 
Table 3. Experimental results of PPUF in CC measured at five irradiance levels: total heat, $\mathrm{CO}_{2}$ and $\mathrm{CO}$ released during a test.

\begin{tabular}{|c|c|c|c|}
\hline $\begin{array}{c}\text { Irradiance level } \\
\text { of } \mathrm{CC} \\
{\left[\mathrm{kW} \cdot \mathrm{m}^{-2}\right]} \\
\end{array}$ & $\begin{array}{c}\text { Total heat } \\
\text { released } \\
{\left[\mathrm{GJ} \cdot \mathrm{m}^{-2}\right]}\end{array}$ & $\begin{array}{c}\text { Total } \mathrm{CO}_{2} \\
\text { released } \\
{\left[\mathrm{g}_{\mathrm{CO} 2} \cdot \mathrm{m}^{-2}\right]} \\
\end{array}$ & $\begin{array}{c}\text { Total } \mathrm{CO} \\
\text { released } \\
{\left[\mathrm{g}_{\mathrm{CO}} \cdot \mathrm{m}^{-2}\right]}\end{array}$ \\
\hline 10 & 15.0 & 1310 & 13.8 \\
\hline 20 & 21.3 & 1855 & 21.6 \\
\hline 30 & 34.6 & 3028 & 29.5 \\
\hline 40 & 35.7 & 3230 & 28.6 \\
\hline 50 & 32.9 & 3029 & 29.9 \\
\hline
\end{tabular}

Table 3 presents total heat, $\mathrm{CO}_{2}$ and $\mathrm{CO}$ released during the full time of sample exposure at five different $\mathrm{CC}$ irradiance levels. The maximum of total heat and $\mathrm{CO}_{2}$ release occurred at an irradiance level of $40 \mathrm{~kW} \cdot \mathrm{m}^{-2}$, while the maximum $\mathrm{CO}$ release occurred under an irradiance of $50 \mathrm{~kW} \cdot \mathrm{m}^{-2}$. The different occurrences of these maxima may be explained by analyzing the MLR and HRR (see Figure 1). The irradiance level in the CC exerted a strong influence on the decomposition rate of the semi-liquid polyol. With increasing irradiance level, the decomposition rate of the semi-liquid increased significantly (second stage). However, with increasing irradiance level, the rate of the breakdown of PPUF molecules and combustion of isocyanate do not vary in the same proportion (first stage). The speed of movement of the decomposition front from top to bottom of the foam slab was not highly different between the different irradiance levels. This explains the fact that the second peak (or inflection) in the HRR curves changed more significantly than the intensity of the first peak with increasing irradiance. The polyol pool fire released a non-negligible amount of energy, which was controlled by thermal balance and heat of gasification of the semi-liquid product.

Table 4 gives yields of the main gas species released during PPUF combustion. Yields measured in experiments can be the basis for extrapolating results of gas species production from bench-scale to full-scale scenarios [8].

Table 4. Yield of the main gas species released during PPUF combustion.

\begin{tabular}{|c|c|c|c|c|c|c|c|c|c|c|c|}
\hline \multirow{3}{*}{$\begin{array}{c}\text { Irradiance } \\
\text { level of CC } \\
{\left[\mathrm{kW} \cdot \mathrm{m}^{-2}\right]}\end{array}$} & \multicolumn{10}{|c|}{ Yield of chemical compounds $\left[\mathrm{g}_{\text {especies }} \cdot \mathrm{g}_{\text {sample }}{ }^{-1}\right]$} & \multirow{3}{*}{$\frac{\mathrm{CO} / \mathrm{CO}_{2}}{[\%]}$} \\
\hline & \multicolumn{2}{|c|}{$\mathrm{CO}_{2}$} & \multicolumn{2}{|c|}{$\mathrm{H}_{2} \mathrm{O}$} & \multicolumn{2}{|c|}{$\mathrm{CO}$} & \multicolumn{2}{|c|}{ NO } & \multicolumn{2}{|c|}{ THC } & \\
\hline & Mean & St. Dev. & Mean & St. Dev. & Mean & St. Dev. & Mean & St. Dev. & Mean & St. Dev. & \\
\hline 10 & 2.69 & 1.06 & 0.92 & 0.95 & 0.036 & 0.023 & 0.003 & 0.002 & 0.104 & 0.117 & $1.34 \%$ \\
\hline 20 & 2.17 & 0.24 & 1.54 & 0.74 & 0.029 & 0.012 & 0.004 & 0.003 & 0.062 & 0.028 & $1.32 \%$ \\
\hline 30 & 2.15 & 0.21 & 0.61 & 0.11 & 0.018 & 0.005 & 0.002 & 0.002 & 0.018 & 0.011 & $0.85 \%$ \\
\hline 40 & 2.32 & 0.39 & - & - & 0.016 & 0.007 & - & - & 0.028 & 0.018 & $0.68 \%$ \\
\hline 50 & 2.31 & 0.69 & 0.78 & 0.46 & 0.019 & 0.009 & 0.003 & 0.002 & 0.032 & 0.019 & $0.82 \%$ \\
\hline Mean & 2.33 & 0.52 & 0.96 & 0.57 & 0.024 & 0.011 & 0.003 & 0.002 & 0.049 & 0.039 & $1.01 \%$ \\
\hline
\end{tabular}

Yields of Table 4 have been calculated for the steady state regime. The transient periods at the beginning and end of tests were not considered for the calculations. Yields of $\mathrm{CO}_{2}, \mathrm{H}_{2} \mathrm{O}$ and THC were at their lowest at an irradiance level of $30 \mathrm{~kW} \cdot \mathrm{m}^{-2}$, with the 
lowest yield of $\mathrm{CO}$ at $40 \mathrm{~kW} \cdot \mathrm{m}^{-2}$. There was no clear dependence of $\mathrm{NO}$ yield on irradiance level. However, accounting for the calculated standard deviations, only $\mathrm{CO}_{2}$ yield measurements are of high consistency. The very limited amount of data found in the literature on the gas product yields of polyurethane foam is listed in Table 5. Note that the polyurethane formulations significantly differ from one type of foam to another.

Table 5. Data in the literature [20][21][22] on yields of gas species released from polyurethane formulations in $\mathrm{CC}$ at various irradiances levels.

\begin{tabular}{|c|c|c|c|}
\hline \multirow{3}{*}{$\begin{array}{c}\text { Irradiance } \\
\text { level of CC } \\
{\left[\mathrm{kW} \cdot \mathrm{m}^{-2}\right]} \\
\end{array}$} & \multicolumn{3}{|c|}{ Yield $\left[g_{\text {especies }} \cdot g_{\text {sample }}{ }^{-1}\right]$} \\
\hline & $\mathrm{CO}_{2}$ & $\mathrm{CO}$ & NO \\
\hline & Mean & Mean & Mean \\
\hline 10 & $0.37^{\mathrm{b}, \mathrm{c}}$ & $0.001^{\mathrm{b}, \mathrm{c}}$ & - \\
\hline 20 & $3.05^{\mathrm{b}}$ & $0.065^{\mathrm{b}, \mathrm{c}}$ & - \\
\hline 30 & $2.59^{\mathrm{b}}$ & $0.055^{\mathrm{b}, \mathrm{d}}$ & - \\
\hline \multirow[t]{2}{*}{35} & $2.43^{\mathrm{a}}$ & $0.014^{\mathrm{a}}$ & $0.011^{\mathrm{a}}$ \\
\hline & $1.26^{\mathrm{e}}$ & $0.037^{\mathrm{e}}$ & - \\
\hline 40 & $2.62^{\mathrm{b}}$ & $0.058^{\mathrm{b}}$ & - \\
\hline 50 & $2.72^{\mathrm{b}}$ & $0.059^{\mathrm{b}}$ & - \\
\hline \multicolumn{4}{|c|}{$\begin{array}{l}{ }^{\mathrm{a}} \text { Source Hertzberg et al. [20] A yield of } \\
0.0015 \mathrm{~g}_{\mathrm{HCN}} \cdot \mathrm{g}_{\text {sample }}{ }^{-1} \text { is also reported }\end{array}$} \\
\hline \multicolumn{4}{|c|}{${ }^{\mathrm{b}}$ Source Kotresh et al. [21] } \\
\hline \multicolumn{4}{|c|}{${ }^{\mathrm{c}}$ Authors reported non-ignition at $10 \mathrm{~kW} \cdot \mathrm{m}^{-2}$} \\
\hline \multicolumn{4}{|c|}{${ }^{\mathrm{d}}$ This value replaces the data of table 2 that } \\
\hline $\begin{array}{l}{ }^{\mathrm{e}} \text { Source Fab } \\
\text { tests with } \mathrm{m}\end{array}$ & $\begin{array}{l}a l .[22] \\
\text { polyure }\end{array}$ & $\begin{array}{l}\text { f results o } \\
\text { am }\end{array}$ & \\
\hline
\end{tabular}

As seen in Table 5, yields of $\mathrm{CO}_{2}$ and $\mathrm{CO}$ measured in this work are in the same order of magnitude as those found by other authors [20][21][22]. A significant difference is found in the $\mathrm{CO}_{2}$ yield for an irradiance level of $10 \mathrm{~kW} \cdot \mathrm{m}^{-2}$, as Kotresh et al. [21] reported non-ignition of the polyurethane sample. Only one data point was found for $\mathrm{NO}$ yield [20], which is 5.5 times larger than the value found in current tests. Also, Hertzberg et al [20] reported a HCN yield of $0.0015 \mathrm{gHCN}^{\cdot \mathrm{g}_{\text {sample }}}{ }^{-1}$. We did not detect HCN in our research, which suggests a possible difference between the two test conditions in either the ventilation conditions or composition of the virgin foam. Hertzberg et al. [20] measured soot production with a low-pressure impactor, reporting a yield close to $2.5 \mathrm{mg} \cdot \mathrm{g}_{\text {sample }}{ }^{-1}$ at an irradiance level of $35 \mathrm{~kW} \cdot \mathrm{m}^{-2}$. This soot yield is small compared to $\mathrm{CO}_{2}$ yield of $2.43 \mathrm{~g} \mathrm{~g}_{\text {sample }}{ }^{-1}$ measured by the same study [20]. Kotresh et al. [21] calculated a ratio between $\mathrm{CO}$ and $\mathrm{CO}_{2}$ mass flows near $2 \%$, while our experiments give a ratio of $1 \%$ for all the irradiance levels (see column $\mathrm{CO} / \mathrm{CO}_{2}$ of Table 4). 
During the burning process, the carbon initially present in the PPUF is converted into gas carbon oxides, THC and soot. Table 6 shows the carbon balance between the burnt fraction of solid PPUF (from Table 1) and carbon contained in the evolved gases. Soot production was not measured, thus the carbon in soot was taken as the difference of carbon in the burnt foam and carbon in the gas products.

Table 6. Carbon balance between the solid (source) and the gas (emissions) phases measured at five irradiance levels.

\begin{tabular}{|c|c|c|c|c|c|}
\hline \multirow{3}{*}{$\begin{array}{c}\text { Irradiance } \\
\text { level of CC } \\
{\left[\mathrm{kW} \cdot \mathrm{m}^{-2}\right]}\end{array}$} & \multicolumn{5}{|c|}{ Carbon balance $[\mathrm{g}]$} \\
\hline & \multirow{2}{*}{$\begin{array}{c}\text { Solid } \\
\text { PPUF }\end{array}$} & \multicolumn{4}{|c|}{ Gaseous products } \\
\hline & & $\mathrm{CO}_{2}$ & $\mathrm{CO}$ & THC & Soot \\
\hline 10 & 3.58 & 3.160 & 0.033 & 0.016 & 0.371 \\
\hline 20 & 4.87 & 4.470 & 0.052 & 0.016 & 0.332 \\
\hline 30 & 7.71 & 7.300 & 0.071 & 0.013 & 0.326 \\
\hline 40 & 7.99 & 7.790 & 0.069 & 0.021 & 0.110 \\
\hline 50 & 7.43 & 7.310 & 0.072 & 0.022 & 0.026 \\
\hline
\end{tabular}

According to data in Table 6, without soot, the resulting carbon balance in gas products accounted for 90\% to 99\% of the total carbon contained in solid PPUF. This is a satisfactory result because solid and gas phases can be analyzed together. Expanded uncertainty of FTIR gas analysis was estimated at the LNE laboratory as being $3.6 \%$ in the range of the gas concentrations found.

Calculations have also been conducted with the measurements to determine the balance of hydrogen and nitrogen present in the solid foam and gas products. It was found that $\mathrm{H}_{2} \mathrm{O}$ accounts for the largest proportion of hydrogen present in the virgin PPUF. A very small proportion was found in THC. Unfortunately, since NO is the only detectable compound containing nitrogen in the product gases, the balance of nitrogen provided here is less precise. The nitrogen contained in the gas released during the combustion process, accounted for only between $2 \%$ and $3 \%$ of the total nitrogen contained in the virgin sample. Two different hypotheses can explain this difference: a) nitrogen may be reduced into $\mathrm{N}_{2}$, which is impossible to detect by the FTIR because it is a symmetric molecule; b) nitrogen did not only form NO, but reacted to form other nitrogenated compounds in very low concentrations that could not be measured in the conditions of dilution generated by cone calorimeter ventilation.

Figure 5 shows curves representing the ratio between $\mathrm{HRR}$ and $\mathrm{CO}_{2}$ mass flow at three cone calorimeter irradiance levels of 10,30 and $50 \mathrm{~kW} \cdot \mathrm{m}^{-2}$. This ratio expresses the equivalent quantity of released heat when one gram of $\mathrm{CO}_{2}$ was produced. 


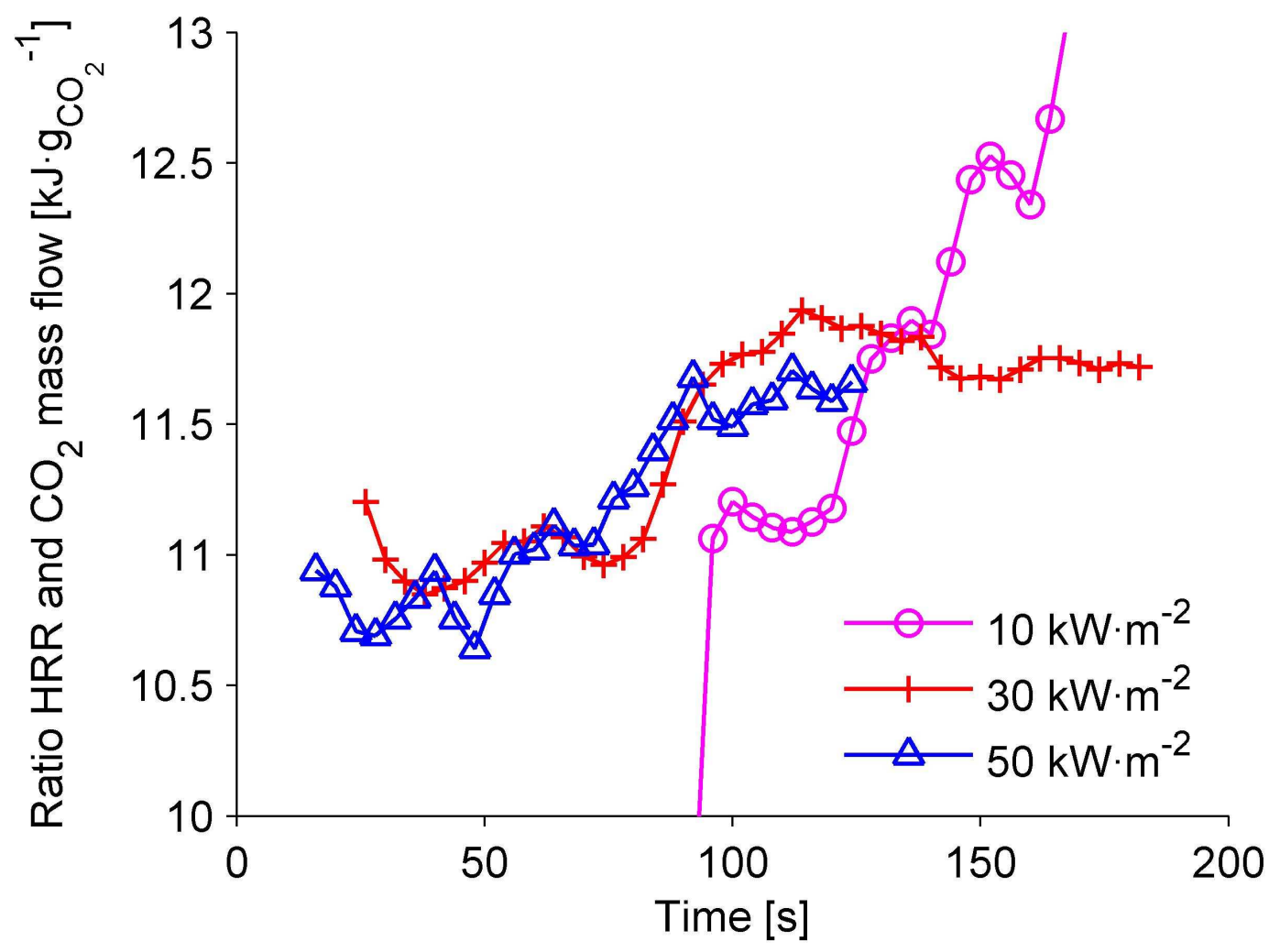

Figure 5. Ratio of HRR to $\mathrm{CO}_{2}$ mass flow at three CC irradiance levels 10,30 and $50 \mathrm{~kW} \cdot \mathrm{m}^{-2}$.

In contrast of the results of Figure 5, for materials with single stage decomposition kinetics (i.e., PMMA), the gas fuel molecules produced over the entire decomposition process are of the same nature and this ratio is therefore constant. During PPUF combustion, at least two different products were burning and each one released a different amount of heat and $\mathrm{CO}_{2}$. The slopes, $a_{i}$, y-intercepts, $b_{i}$, and the least squares fit factors, $R_{i}^{2}$, of straight lines that best fit the three curves in Figure 5 are respectively: $a_{10}=0.038, b_{10}=6.6, R_{10}^{2}=0.87 ; a_{30}=0.0068, b_{30}=10.7, R_{30}^{2}=0.68 ; a_{50}=0.011$, $b_{50}=10.4, R_{50}^{2}=0.88$.

Figure 6 shows for three irradiance levels the ratio between HRR and Specific Mass-Loss Rate (SMLR), which is defined as the mass-loss rate by sample unit area. This ratio is equivalent to the Effective Heat of Combustion (EHC). 


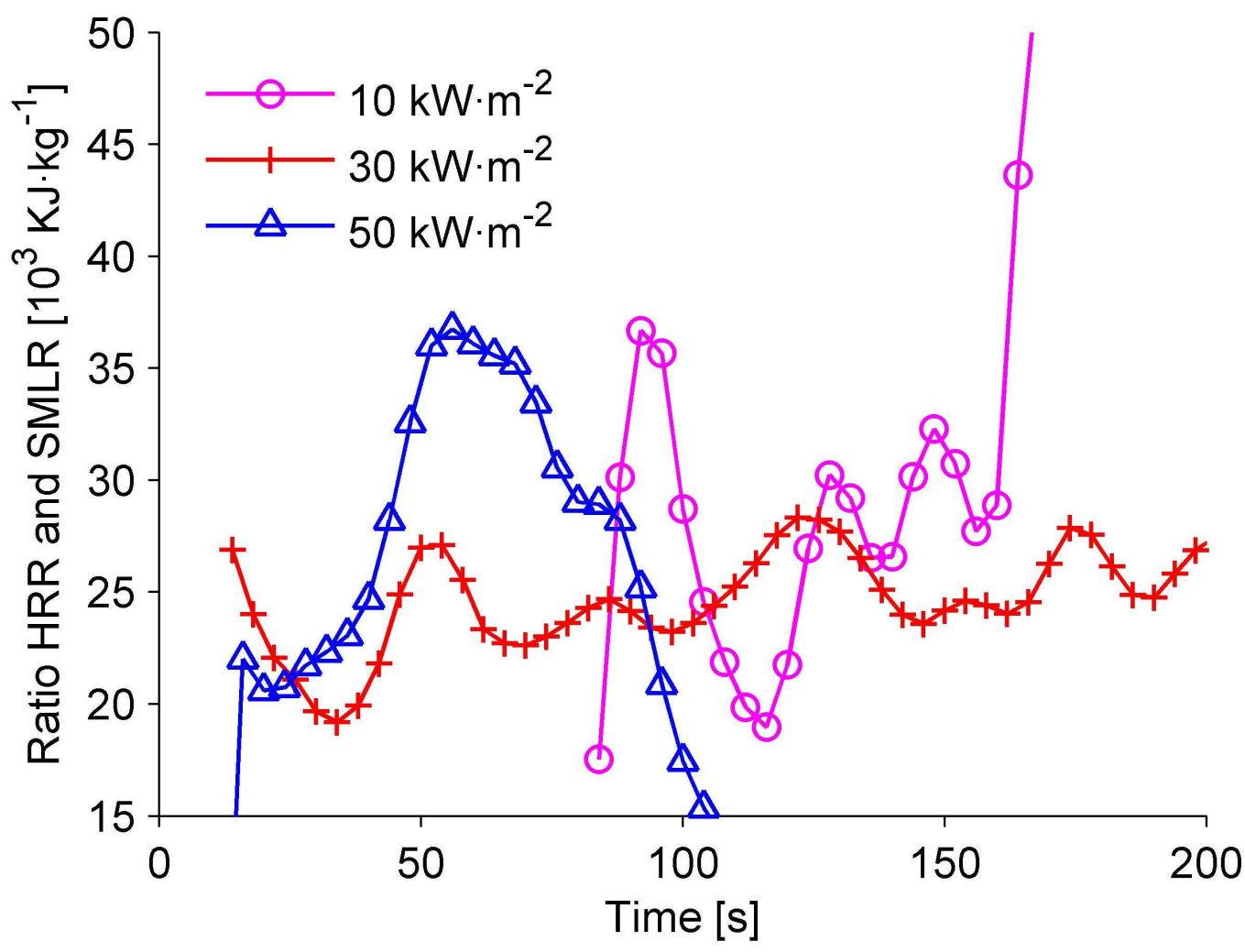

Figure 6. Ratio of HRR to SMLR (i.e. the EHC) for three irradiance levels 10,30 and $50 \mathrm{~kW} \cdot \mathrm{m}^{-2}$.

In general, the EHC is seen to vary in time and also depends on the irradiance level with values ranging from 20000 to $40000 \mathrm{~kJ} \cdot \mathrm{kg}^{-1}$ with the average at 26134 $\mathrm{kJ} \mathrm{kg}^{-1}$. The mean and standard deviations for each irradiance level are calculated and presented in Table 7. The highest EHC values are found at the extreme irradiance levels 10 and $50 \mathrm{~kW} \cdot \mathrm{m}^{-2}$, but have standard deviations of up to $20.6 \%$ and $21.3 \%$ with respect to the mean value. For irradiance levels between 20 and $40 \mathrm{~kW} \cdot \mathrm{m}^{-2}$, the standard deviations are between $6 \%$ and $10 \%$.

Babrauskas [8], reported an EHC value of $23900 \mathrm{~kJ} \cdot \mathrm{kg}^{-1}$ for a polyurethane with the chemical formula $\mathrm{CH}_{1.13} \mathrm{O}_{0.33} N_{0.16}$, with a molecular weight $20.63 \mathrm{~g} \cdot \mathrm{mol}^{-1}$ (for reference, the molecular weight of the foam used in our study is $19.10 \mathrm{~g} \cdot \mathrm{mol}^{-1}$ ). Babrauskas [8], also reports a general range of EHC values between 26100 and $31600 \mathrm{~kJ}^{-1} \mathrm{~kg}^{-1}$ for a wide variety of flexible polyurethane foam formulations in the market. The EHC value for the material in this work is closer to the lower limit of the range reported by Babrauskas. Hirschler in reference [8], presented HRR curves of nonfire retarded polyurethane foam at three cone calorimeter irradiance levels of 20,40 and $70 \mathrm{~kW} \cdot \mathrm{m}^{-2}$. Their respective maxima of heat release rates were near 290,710 and $1220 \mathrm{~kW} \cdot \mathrm{m}^{-2}$, while in our research, irradiance levels of 20 and $40 \mathrm{~kW} \cdot \mathrm{m}^{-2}$ resulted in HRR maxima at 300 and $330 \mathrm{~kW} \cdot \mathrm{m}^{-2}$. The shapes of the HRR curves found by Hirschler [8], were not the same as those found in this research. The author reported two peaks, with the intensity of the first lower than the second, while in our research, the first peak is always higher than the second. This means that even if the two foams had a similar 
density, the kinetics of solid decomposition differed probably because of the composition.

Table 7. Mean and standard deviation of the effective heat of combustion (EHC) measured at five irradiance levels.

\begin{tabular}{|c|c|c|}
\hline \multirow{3}{*}{$\begin{array}{c}\text { Irradiance level } \\
\text { of } \mathrm{CC} \\
{[\mathrm{kW} \cdot \mathrm{m}-2]}\end{array}$} & \multicolumn{2}{|c|}{$\mathrm{EHC}=\mathrm{HRR} / \mathrm{SMLR}$} \\
\hline & Mean & St. Dev. \\
\hline & \multicolumn{2}{|c|}{$\left[\mathrm{kJ} \cdot \mathrm{kg}^{-1}\right]$} \\
\hline 10 & 26379 & 5443 \\
\hline 20 & 25665 & 2743 \\
\hline 30 & 24502 & 2577 \\
\hline 40 & 25658 & 1698 \\
\hline 50 & 28467 & 6061 \\
\hline Mean & 26134 & 3704 \\
\hline
\end{tabular}

\section{Conclusions}

The experimental results of burning of non-fire-retarded polyether polyurethane foam are presented. Experiments were carried out in the cone calorimeter at various irradiance levels and analysis of the gas products was performed using FTIR, FID and ND-IR. The analysis allowed studying the different stages in the kinetics and quantification of the gas composition. Of the twenty-two different gas species that were monitored simultaneously, the main species found were $\mathrm{CO}_{2}, \mathrm{CO}, \mathrm{H}_{2} \mathrm{O}, \mathrm{NO}$ and THC.

Two decomposition stages were clearly identified. In the first stage, polyurethane molecules break down and release isocyanate, which is characterized by the detection of $\mathrm{CO}, \mathrm{NO}$ and THC gases. The second stage involves the combustion of polyol, which is characterized by the formation of $\mathrm{H}_{2} \mathrm{O}$. Cone calorimeter tests were performed without an insulating layer at the rear face of the PPUF slab. The thermal mechanism for PPUF decomposition proposed in this work is valid for the five irradiance levels studied. The two stages observed are in agreement with the decomposition mechanism proposed in literature [12][13][14] but the data presented here is, to the best knowledge of the authors, the first experimental study of PPUF burning behavior taking into account the release of gas species too.

The yields of major gases released during steady state combustion were calculated. Results were compared with data available in the literature, showing very good correlation.

Foam characterization is carried out by an elementary analysis of the matrix, with the raw chemical formula as $\mathrm{CH}_{1.53} \mathrm{O}_{0.27} \mathrm{~N}_{0.08}$. The chemical formula allows carbon, hydrogen and nitrogen to be balanced between burned mass and gas products. Carbon 
L Bustamante Valencia, T Rogaume, E Guillaume, G Rein, JL Torero, Analysis of Principal Gas Products During Combustion of Polyether Polyurethane Foam at Different Irradiance Levels, Fire Safety Journal 44, pp.933-940, 2009. doi:10.1016/j.firesaf.2009.05.003

and hydrogen balances are accurate, but the nitrogen balance is not, with only $3 \%$ of total nitrogen content in the solid foam accounted for in the gases.

The ratio between HRR and $\mathrm{CO}_{2}$ releases were calculated. The EHC was not constant and depended on irradiance level with an average value of $26134 \mathrm{~kJ} \mathrm{~kg}^{-1}$. The $\mathrm{EHC}$ results correspond to polyurethane EHC values found in literature.

Future work will aim at determining the influence of oxygen concentration in PPUF decomposition kinetics.

\section{Acknowledgements}

The authors want to acknowledge Franck Didieux, Laurent Saragoza and Damien Lesenechal for their invaluable technical support during this research. Thanks to Carine Chivas for her pertinent comments. Thanks to SCA CNRS for their laboratory analysis. The help of the Editor of the Fire Safety Journal, Prof. Dougla Drysdale, to improve the clarity of this manuscript is greatly appreciated.

\section{References}

[1] IAL CONSULTANTS. PU chemicals and products in Europe, Middle East \& Africa (EMEA), 2007. http://www.ialconsultants.com/

[2] BEYLER C, HIRSCHLER M. Thermal decomposition of polymers. SFPE Handbook of Fire Protection Engineering. Second Ed. Section 1, Chapter 7, P. 99-199, 1995.

[3] SAINRAT A. Regulatory trends and standardization towards the reaction to fire of the upholstery furniture in France and in Europe. Flame Retardants 2006 Proceedings.

[4] ISO 291:2005. Plastics - Standard atmospheres for conditioning and testing. ISC: 83.080 .01 .

[5] ISO 5 66o-1:2002 Reaction-to-fire tests - Heat release, smoke production and mass loss rate - Part 1 Heat Release rate (cone calorimeter method) Second edition 2002.

[6] BRABRAUSKAS V, PEACOCK R. Heat release rate: The single most important variable in fire hazard. Fire Safety Journal, 1992. Vol. 18, P. 255-272.

[7] BABRAUSKAS V. Ignition Handbook. Fire Sciences Publishers, 2003. ISBN 0-9728111-3-3.

[8] BABRAUSKAS V, GRAYSON S. Heat release in fires. Elsevier Science Publishers Ltd. Essex - England, 1992. ISBN 1-85166-794-6.

[9] WICHMAN I. Material Flammability, combustion, toxicity and fire hazard in transportation. Progress in Energy and Combustion Science 29 (2003) 247-299. 
[10] NORMANT H, NORMANT J. Chimie organique - Cours de chimie. Masson et Cie, Editeurs. 2 édition, 1968.

[11] MAROTEL Y. Polyuréthannes. Techniques de l'ingénieur, traité de Plastiques et Composites. AM 3425 (2000). P. 1-18.

[12] SAUNDERS J, BACKUS J. Thermal degradation and flammability of urethane polymers. Rubber Chemistry and Technology 39 (1961) 461-48o.

[13] WOOLLEY W. Nitrogen-containing products from the thermal decomposition of flexible polyurethane foams. British Polymer Journal, 1972, 4, 27-43.

[14] ROGERS F, OHLEMILLER T. pyrolysis kinetics of polyurethane foam by thermogravimetry; a general kinetic method. Journal of Macromolecular Science A 15 (1), P. 169-185 (1981).

[15] RASBASH D, DRYSDALE D. Fundamentals of smoke Production. Fire Safety Journal. Vol. 5, No. 1, P. 77-86. 1982.

[16] PAL G, MACSKAZY H. Plastics - Their behavior in fires. Elsevier Sciences Publishers. The Netherlands, 1991. ISBN: 0-44-98766-5.

[17] GUILLAUME E. Effets du feu sur les personnes. Synthèse bibliographique. Laboratoire national de métrologie et d'essais (LNE). 2006.

[18] OHTANI H., KIMURA T., OKAMOTO K., TSUGE S., Characterization of Polyurethanes by High-Resolution Pyrolysis-Capillary Gas Chromatography. Journal of Analytical and Applied Pyrolysis 12 (1987) 115-133.

[19] BITEAU H, STEINHAUS T, SCHEMEL C, SIMEONI A, MARLAIR G, BAL N, TORERO J.L. Calculation methods for the heat release rate of materials of unknown composition. Proceedings of the $9^{\text {th }}$ International Symposium of Fire Safety Science 2008.

[20] HERTZBERG T, BLOMQVIST P, DALENE M, SKARPING G. Particles and isocyanates from fires. SP Swedish National Testing and Research Institute, 2003:05: Boras, 2003.

[21] KOTRESH $\mathrm{T}$ et al. Effect of heat flux on the burning behaviour of foam and foam/Nomex III fabric combination in the cone calorimeter. Polymer Testing 25 (2006) 744-757.

[22] FABIAN T, GANDHI P. Smoke characterization project. Technical report. NFPA - Underwriters Laboratories Inc. 2007. http://www.nfpa.org/

L Bustamante Valencia, T Rogaume, E Guillaume, G Rein, JL Torero, Analysis of

Principal Gas Products During Combustion of Polyether Polyurethane Foam at Different

Irradiance Levels, Fire Safety Journal 44, pp. 933-940, 2009. doi:10.1016/

j.firesaf.2009.05.003 